\title{
Isoferulic acid inhibits human leukemia cell growth through induction of G2/M-phase arrest and inhibition of Akt/mTOR signaling
}

\author{
ZHIGUO LONG $^{1 *}$, GUANGJIA FENG $^{1 *}, \mathrm{NA} \mathrm{ZHAO}^{1}$, LEI WU $^{1}$ and HONGBO ZHU ${ }^{2}$ \\ Departments of ${ }^{1}$ Hematology and ${ }^{2}$ Pathology, Shanghai Pudong Hospital, Fudan University, Shanghai 201399, P.R. China
}

Received May 25, 2019; Accepted October 15, 2019

DOI: $10.3892 / \mathrm{mmr} .2020 .10926$

\begin{abstract}
Hematologic malignancy is a serious disease that develops quickly and aggressively, severely threatening human health owing to its high mortality. The current study aimed to evaluate the antitumor effects of isoferulic acid (IFA) on leukemia cells and investigate the possible molecular mechanisms. Hematologic cancer cell lines (Raji, K562 and Jurkat) were treated with IFA in a dose-dependent manner and proliferation was measured by a cell proliferation assay. Cell cycle arrest was detected via flow cytometry using propidium iodide (PI) staining. Cell apoptosis and apoptosis-associated signal pathways were analyzed via Annexin V/PI staining and western blot assays, respectively. IFA inhibited cell viability, induced cell apoptosis and triggered cell cycle arrest in G2/M phase in Raji, K562, and Jurkat cells in a dose-dependent manner. In response to IFA treatment, the levels of cleaved poly(ADP-ribose) polymerase and cleaved caspase-3 were increased in Jurkat and K562 cells, which was associated with increased phosphorylation of $\mathrm{Cdc} 2$ and reduction of Cyclin B1 levels. IFA remarkably attenuated the phosphorylation of mTOR and Akt in Jurkat cells. Collectively, the present data suggested that IFA had therapeutic effects on Jurkat, K562, and Raji cells, indicating it as a promising candidate for the treatment of hematologic malignancy.
\end{abstract}

\section{Introduction}

Hematologic malignancy is a serious disease that develops quickly and aggressively, and severely threatens human health due to its high mortality (1-3). The incidence of complete remission of hematologic malignancy has increased recently,

Correspondence to: Dr Hongbo Zhu, Department of Pathology, Shanghai Pudong Hospital, Fudan University, Building 3, 2800 Gongwei Road, Pudong New Area, Shanghai 201399, P.R. China E-mail: bonniezhu2009@163.com

\section{${ }^{*}$ Contributed equally}

Key words: isoferulic acid, hematologic malignancy, apoptosis, cell cycle arrest, Akt/mTOR signaling with new therapeutic strategies (4). For instance, chimeric antigen receptor (CAR) T-cells targeting CD19 and therapeutic antibodies targeting CD20 have been developed and tested in patients with B-cell lymphoma in preclinical and clinical trials (5). However, there is no effective treatment for T-cell lymphoma, and the treatment of hematologic malignancy is relatively limited. Since the 5-year survival rate of patients with leukemia is between $45-55 \%$ (6-8), developing new therapeutic strategies and finding new agents for curing hematologic malignancy has become urgent.

Isoferulic acid (IFA), also known as 3-(3-hydroxy4-methoxyphenyl)-2-propenoic acid, is a natural compound extracted from Cimicifuga heracleifolia $(\mathrm{CH})$, which is frequently used in traditional medicine in Asian countries for treating inflammatory diseases and specific cancers $(9,10)$. As one of the important active ingredients in $\mathrm{CH}$, IFA has several therapeutic effects. These include the inhibition of several inflammatory diseases (11), elimination of viral infections (12), clearance of reactive oxygen species (ROS) (13), alleviation of metabolic diseases (14) and the reduction of glucose-induced glycation of bovine serum albumin $(11,15)$. Although IFA affects cell cycle arrest (16), inhibits tumor cell proliferation and prompts cell apoptosis (17-19), whether it inhibits leukemia cells remains to be clarified. In vitro and in vivo experiments should be carried out to show whether IFA could become a potential candidate for treating leukemia.

Leukemia is a hematologic malignancy that generally originates in the bone marrow, and develops numerous abnormal leukocytes (20). Abnormal undifferentiated leukocytes dramatically proliferate, expand and resist cell apoptosis, resulting in immature cells in the bone marrow and peripheral blood (21). Inhibition of tumor cell growth and promotion of cell apoptosis are two frequent intervention strategies for eliminating cancer cells (22). Protein kinase B (Akt), a main downstream signal of PI3K, is an important protein in promoting cell proliferation, differentiation, migration and angiogenesis, while also protecting cancer cells against apoptosis (23-25). Activated Akt promotes cell proliferation by activating ribosomal protein S6 kinase and eukaryotic initiation factor 4E (26). It also modulates the cell cycle and drives the cells to go through both G1/S and G2/M cell cycle checkpoints (27). Cyclin B-Cdc2 (also known as Cdk1) is an important complex for the regulation of G2/M transition; it is negatively modulated by Weel and myelin transcription factor 
1 , and positively regulated by Cdc25B. Both modulatory cell signaling pathways are precisely controlled by Akt (28-30). Therefore, interventions that target Akt-mediated cell signals may be able to inhibit cancer.

In the present study, IFA was found to inhibit cell growth and promote cell apoptosis in Jurkat, K562 and Raji cell lines. Leukemia cells were significantly arrested in $\mathrm{G} 2 / \mathrm{M}$ phase, due to the increased phosphorylation of $\mathrm{Cdc} 2$ and reduced expression of Cyclin B1 after treatment with IFA. Furthermore, the latter was identified to attenuate the phosphorylation of mTOR and Akt. The results indicated that IFA has an impact on leukemia in vitro and may be a promising candidate for treating hematologic malignancy.

\section{Materials and methods}

Reagents and antibodies. IFA was ordered from TargetMol. Cell Counting Kit-8 (CCK-8) and trypan blue staining cell viability assay kits were ordered from Beyotime Institute of Biotechnology. An Annexin V-FITC/propidium iodide (PI) apoptosis detection kit was purchased from BestBio Biotechnology. Cleaved poly(ADP-ribose) polymerase (PARP cat. no. 5625), cleaved caspase-3 (cat. no. 9661), b-actin (cat. no. 3700), phosphorylated (p)-Cdc2 (Tyr15) (cat. no. 4539), total-Cdc2 (cat. no. 9116), Cyclin B1 (cat. no. 12231), p-Akt (Thr308) (cat. no. 13038), total-Akt (cat. no. 4685), p-mTOR (Ser2448) (cat. no. 5536) and total-mTOR (cat. no. 2983) were ordered from Cell Signaling Technology, Inc. Horseradish peroxidase (HRP)-conjugated anti-mouse/rabbit IgG antibody was ordered from Jackson ImmunoResearch (cat. no. 111-035-003). Other chemical reagents were purchased from Sigma-Aldrich; Merck KGaA.

Cells and cell culture. Jurkat (acute lymphoid leukemic T cells), K562 (chronic myeloid leukemia), and Raji (Burkitt's lymphoma) cells were purchased from American Type Culture Collection and maintained in RPMI-1640 medium with $10 \%$ FBS (both Gibco; Thermo Fisher Scientific, Inc.) at $37^{\circ} \mathrm{C}$ in a humidified incubator containing $5 \% \mathrm{CO}_{2}$.

Cell viability assay. CCK- 8 assay was applied to detect the cell viability. Briefly, cells were seeded into 96 -well plates at $2 \times 10^{4}$ cells/well for $24 \mathrm{~h}$. IFA at 5,15 and $45 \mu \mathrm{M}$ was added for 12, 24 and $48 \mathrm{~h}$. CCK- $8(10 \mu \mathrm{l})$ was added and the absorbance at $450 \mathrm{~nm}$ was measured after incubation for $2 \mathrm{~h}$. In addition, the trypan blue staining cell viability assay kit was used to detect cell proliferation. Raji, K562 and Jurkat cells were planted into $10-\mathrm{cm}$ dishes at $1 \times 10^{6}$ cells/dish. After cell culture for 5 days, at the point of cell treatment, the cells were collected, stained with trypan blue within 2 min and counted by a hemocytometer at room temperature. The IFA-untreated cell group was normalized to $100 \%$ cell viability.

Cell cycle assay. Cell cycle was determined by using PI staining. Briefly, cells were seeded at a density of $5 \times 10^{5}$ cells $/ \mathrm{ml}$ in 12-well plates for $12 \mathrm{~h}$. Then, cells were treated with IFA at 5,15 and $45 \mu \mathrm{M}$. After incubation for $24 \mathrm{~h}$, cells were collected and fixed with $70 \%$ ethanol overnight at $4^{\circ} \mathrm{C}$. After removing ethanol and neutralizing RNA, PI was used to stain DNA at
A
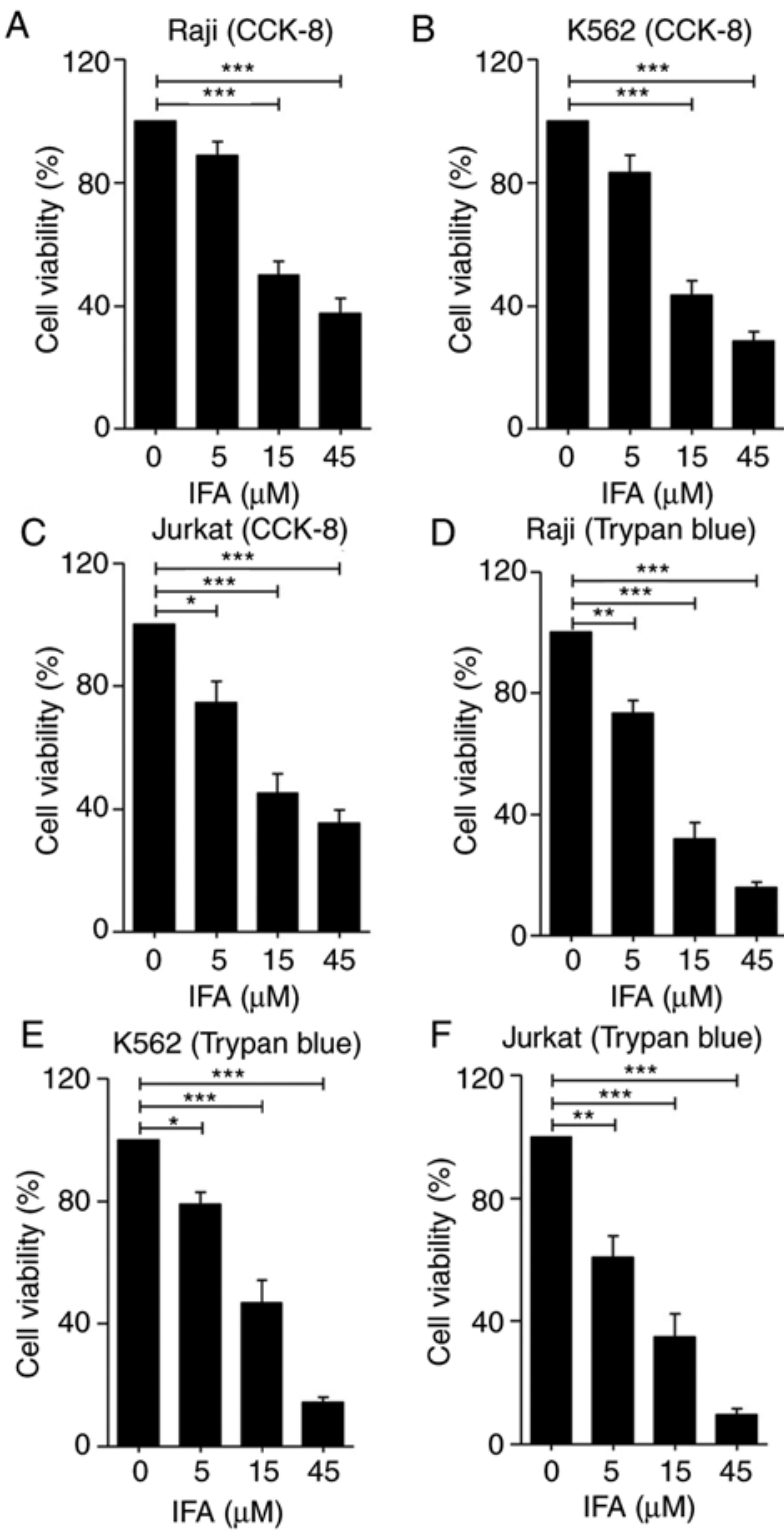

F Jurkat (Trypan blue)

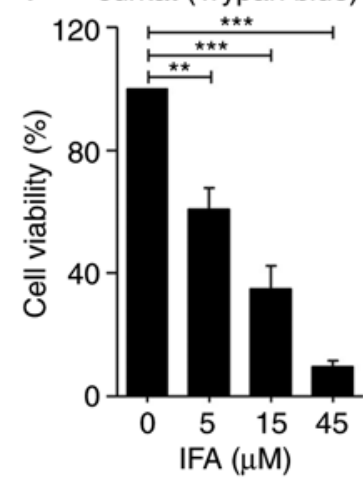

Figure 1. IFA inhibits leukemia cell proliferation in dose-dependent manner. Raji, K562 and Jurkat cells were incubated with IFA at $0,5,15$, and $45 \mu \mathrm{M}$ for $24 \mathrm{~h}$. (A-C) CCK-8 and (D-F) trypan blue assays were performed to evaluate the anti-proliferation effect of IFA on Raji, K562 and Jurkat cells. Data are expressed as mean \pm S.D. of three independent experiments. ${ }^{*} \mathrm{P}<0.05$ ${ }^{* *} \mathrm{P}<0.01,{ }^{* * *} \mathrm{P}<0.001$ vs. control group. CCK-8, Cell Counting Kit-8; IFA, isoferulic acid.

$4^{\circ} \mathrm{C}$. Afterwards, flow cytometry was used to analyze cell cycle distribution (FACSCalibur, BD Biosciences; FlowJo 7.6, FlowJo LLC).

Cell apoptosis analysis. Annexin V-FITC/PI analysis (Qiaoxin) was applied to detect cell apoptosis. Briefly, cells were seeded onto 12 -well plates at $5 \times 10^{5}$ cells overnight. After treatment with $0,5,15$ and $45 \mu \mathrm{M}$ of IFA for $24 \mathrm{~h}$, cells were harvested and rinsed with PBS. Then, cells were resuspended with binding buffer. The Annexin V-FITC and PI were incubated with cells for $15 \mathrm{~min}$ and $5 \mathrm{~min}$ at $4^{\circ} \mathrm{C}$, respectively. Finally, flow cytometry was used to analyze the percentages of apoptotic cells (FACSCalibur; BD Biosciences; FlowJo 7.6, FlowJo LLC). 
A
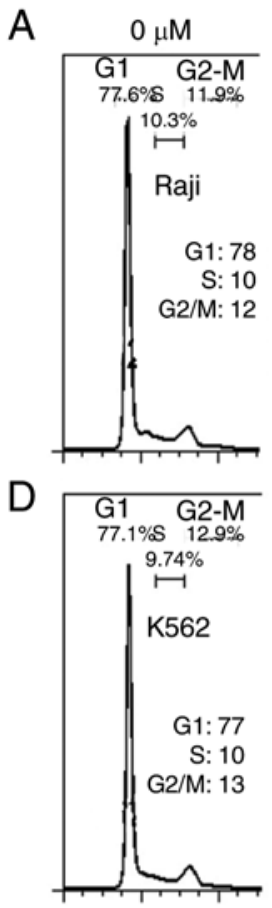

G

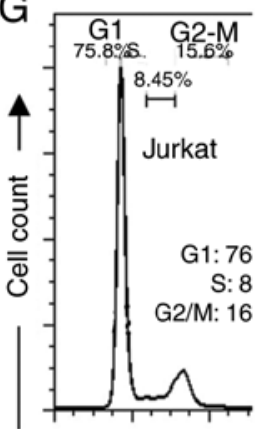

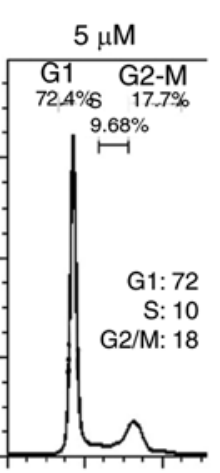
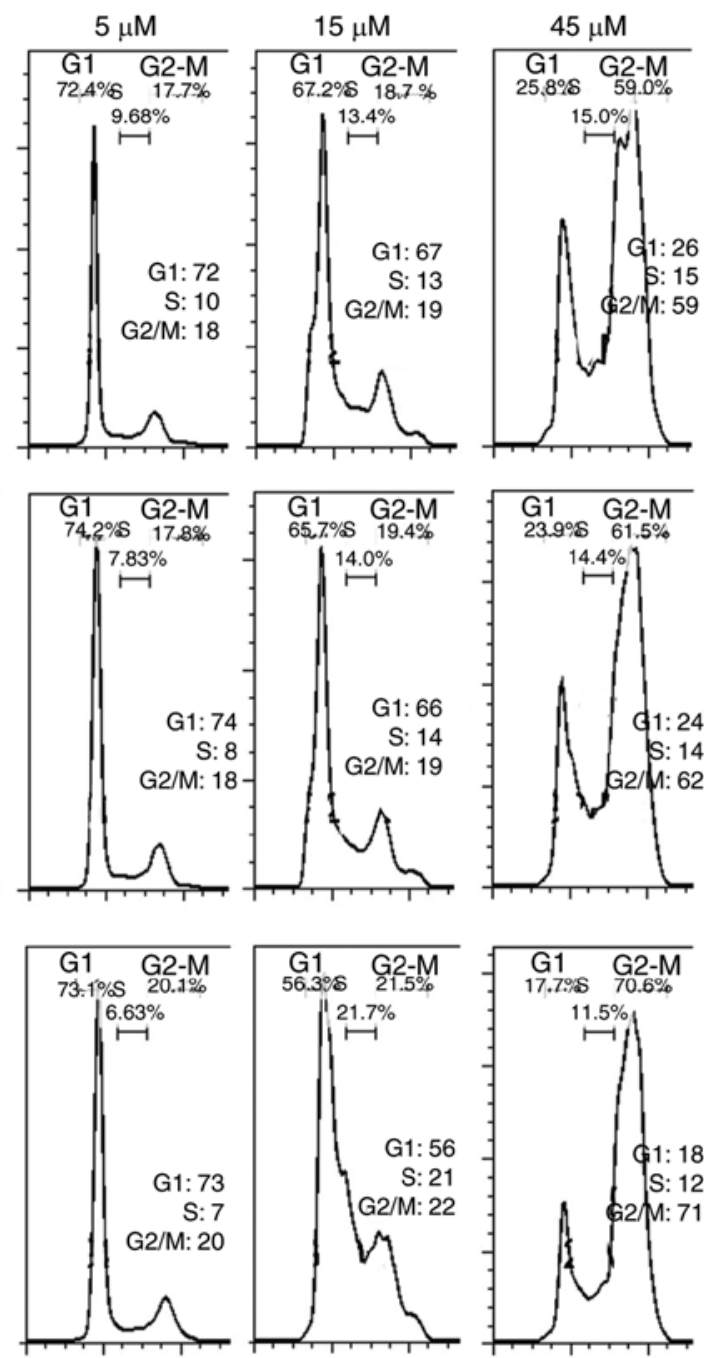

Propidium iodide
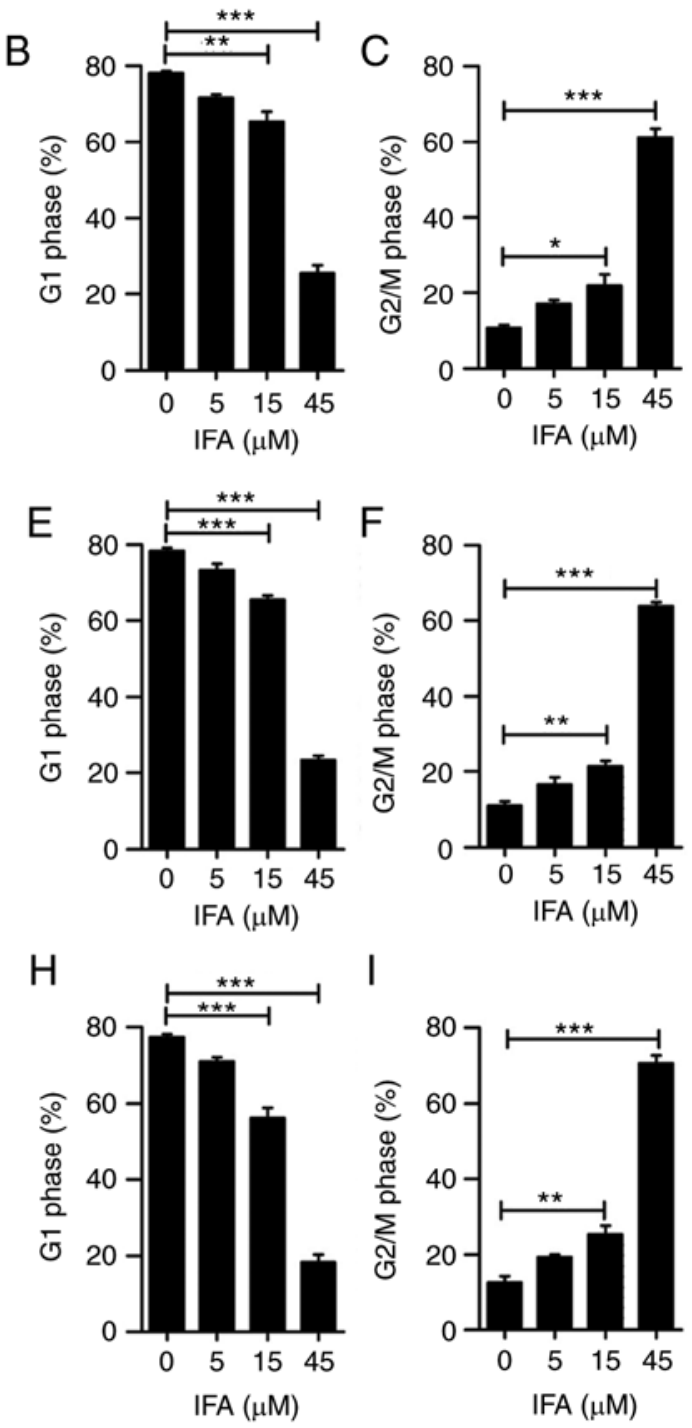

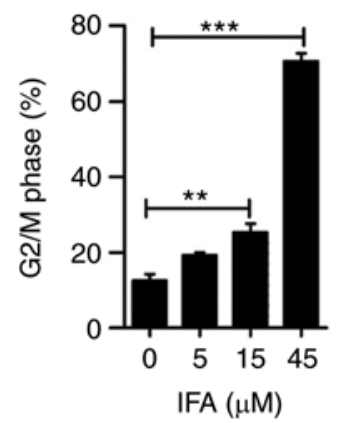

Figure 2. IFA treatment increases cell cycle arrest at G2/M phase and reduces the proportions of cells in G1 and S phase in Raji, K562 and Jurkat cells. (A-C) Raji, (D-F) K562 and (G-I) Jurkat cells were incubated with IFA at 0, 5, 15 and $45 \mu \mathrm{M}$ for $24 \mathrm{~h}$. Then, cells were harvested and fixed overnight. Flow cytometry were used to monitor and analyze cell distribution after staining with propidium iodide. Percentage of Raji, K562 and Jurkat cells in different cell cycles was quantified. Data are expressed as mean $\pm \mathrm{SD}$ of three independent experiments. ${ }^{*} \mathrm{P}<0.05,{ }^{* *} \mathrm{P}<0.01,{ }^{* * *} \mathrm{P}<0.001$ vs. control group. IFA, isoferulic acid.

Western blot analysis. Cells were treated with IFA at 5, 15 and $45 \mu \mathrm{M}$ for $24 \mathrm{~h}$. Then, cells were lysed with RIPA Lysis Buffer and the protein concentration were determined by BCA protein assay and the protein lysis mixed with loading control (all from Beyotime Institute of Biotechnology) and heated at $100^{\circ} \mathrm{C}$ for $5 \mathrm{~min}$. Samples $(20 \mu \mathrm{g})$ were loaded on $10 \%$ of SDS-PAGE gels and transferred to nitrocellulose membranes. Before incubation with different antibodies $(1: 1,000)$ overnight at $4^{\circ} \mathrm{C}$, the membranes were blocked with $5 \%$ non-fat milk for $2 \mathrm{~h}$ at room temperature. After being washed with TBS-Tween 20 (TBST containing $0.1 \%$ Tween 20) five times every $5 \mathrm{~min}$, the membranes were incubated with HRP-conjugated secondary antibodies for another $2 \mathrm{~h}$ at room temperature and then washed with TBST three times. The protein bands were visualized using chemiluminescent substrate reagent (Shanghai Shenger Biotechnology Co., Ltd.). The semi-quantitative analysis was performed by using ImageJ software (v1.48U; National Institute of Health).
Statistical analysis. The data were presented as means \pm SD based on at least three independent experiments. The statistical analysis was performed using Prism 5 (GraphPad Software, Inc). One-way ANOVA followed by Bonferroni post hoc test were used to determine the difference between groups. $\mathrm{P}<0.05$ was considered a statistically significant difference.

\section{Results}

IFA displays anti-proliferation activity in Raji, K562 and Jurkat cell lines. To determine the effect of IFA on proliferation of leukemia cells, Raji, K562 and Jurkat cells were treated with IFA for $24 \mathrm{~h}$ with $0,5,15$ and $45 \mu \mathrm{M}$, and cell viability was investigated using CCK-8 and trypan blue staining assays. As presented in Fig. 1A, IFA showed a significant inhibitory effect on Raji cell growth in a dose-dependent manner. After $24 \mathrm{~h}$, the viable cells decreased by $30( \pm 7) \%-65( \pm 9) \%$ in the presence of 5-45 $\mu \mathrm{M}$, compared with that of the control group. Furthermore, similar inhibitory effects of IFA on K562 

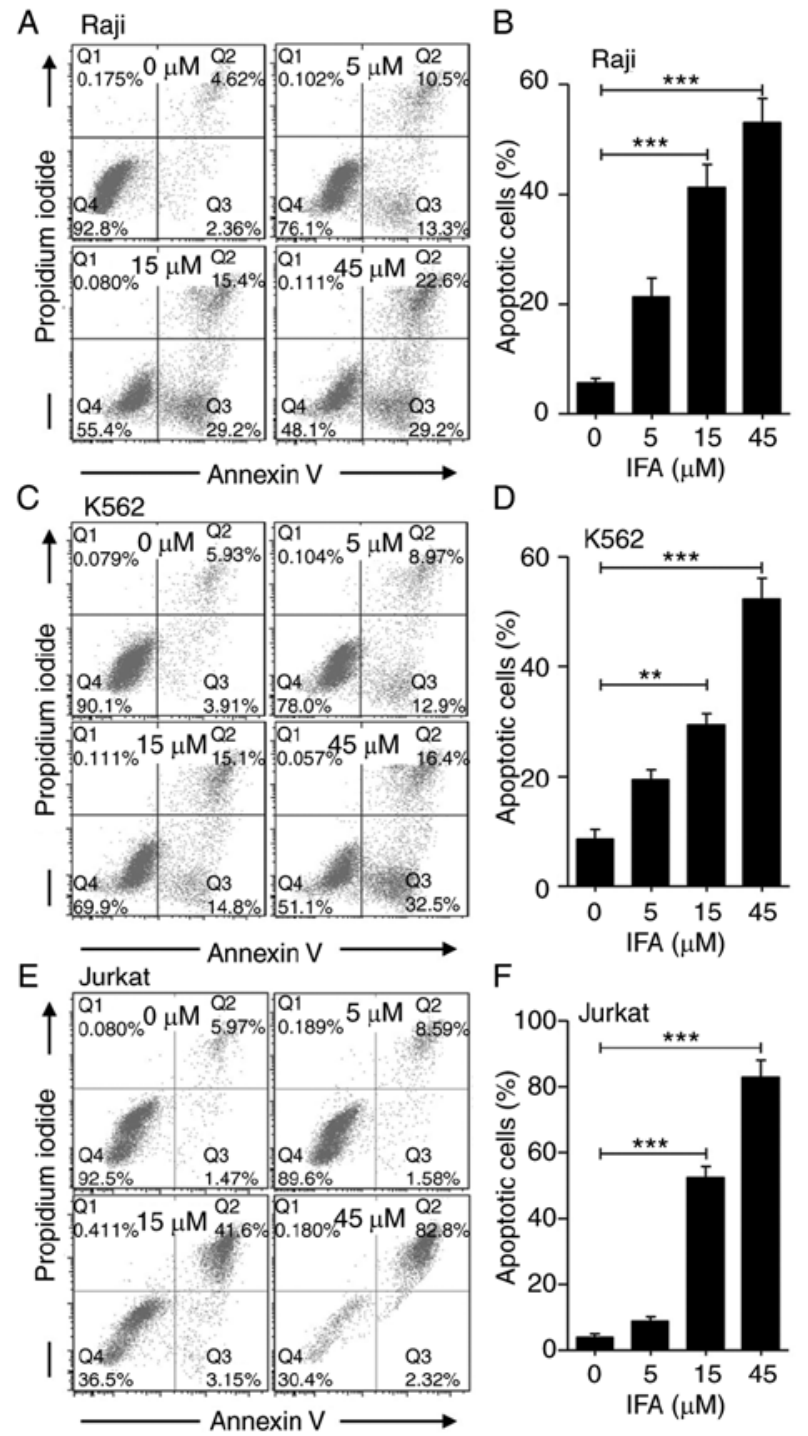

Figure 3. IFA prominently induces cell apoptosis in a dose-dependent manner. (A) Raji, (C) K562 and (E) Jurkat cells were treated with IFA at the indicated concentration for $24 \mathrm{~h}$ and analyzed by flow cytometry following Annexin-FITC and propidium iodide double-staining. The percentages of apoptotic (B) Raji, (D) K562 and (F) Jurkat cells were evaluated in three separate experiments. Data are expressed as mean $\pm \mathrm{SD}$ of three independent experiments. ${ }^{* *} \mathrm{P}<0.01,{ }^{* * *} \mathrm{P}<0.001$ vs. control group. IFA, isoferulic acid.

(Fig. 1B) and Jurkat cells (Fig. 1C) were also detected. To further confirm the anti-proliferative effect of IFA on leukemia cells, a trypan blue staining cell viability assay kit was used to detect the amount of live cells. Raji, K562 and Jurkat cells were incubated with IFA at $0,5,15$ and $45 \mu \mathrm{M}$ for 5 days. The total amount of cells was calculated and the percentage of cell viability was presented in Fig. 1D-F. Similarly, IFA dose-dependently inhibited the proliferation of Raji, K562 and Jurkat cells (Fig. 1D-F). These results indicated that IFA inhibited leukemia cell proliferation.

IFA induces cell cycle arrest at G2/M of Raji, K562 and Jurkat cells. The effect of IFA on cell cycle arrest in Raji, K562 and Jurkat cells was measured by flow cytometry. Raji, K562 and Jurkat cells were treated with IFA at $0,5,15$ and $45 \mu \mathrm{M}$ for $24 \mathrm{~h}$. As presented in Fig. 2A, IFA treatment increased the percentage of Raji cells in $\mathrm{G} 2 / \mathrm{M}$ phase in a dose-dependent
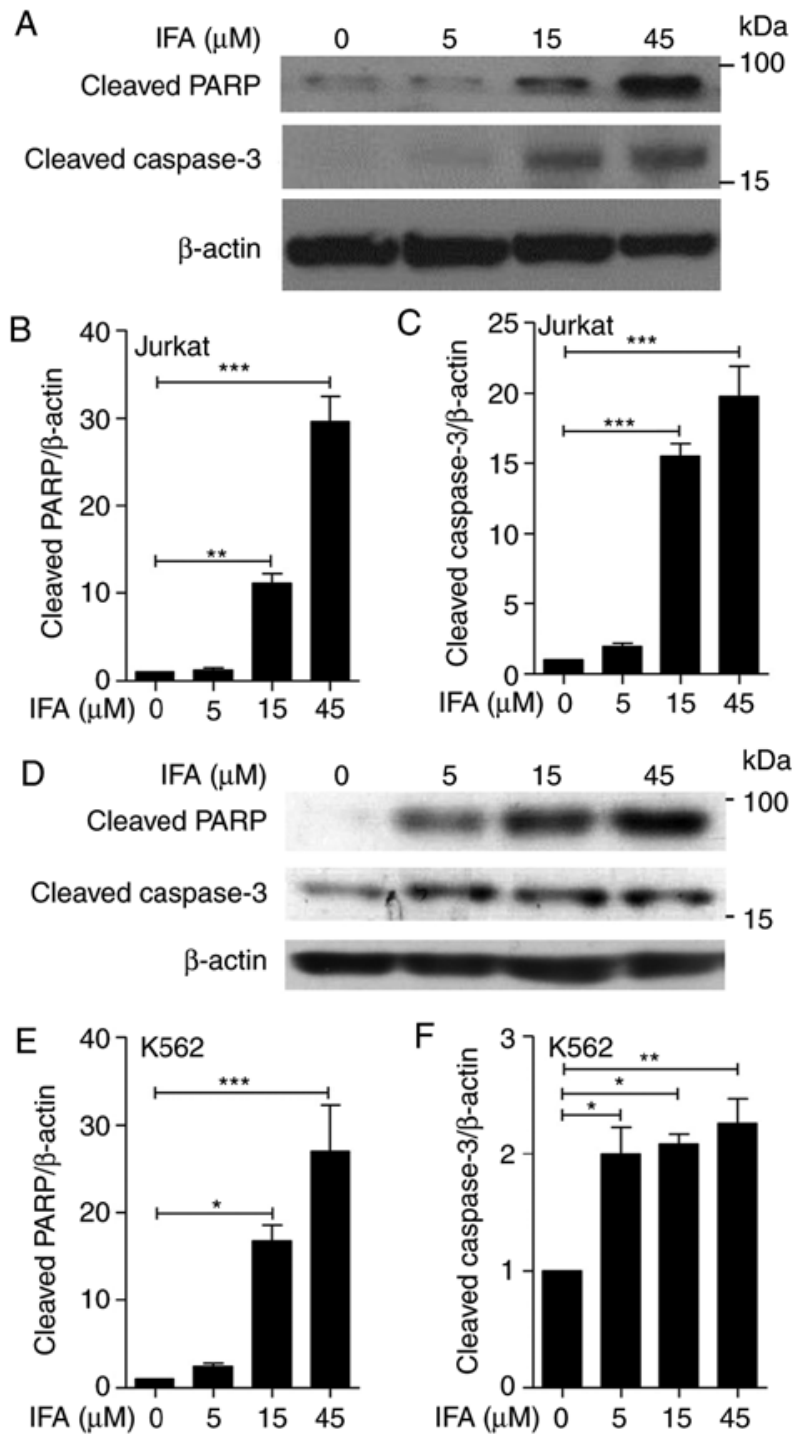

Figure 4. IFA enhances the expression of cleaved PARP and cleaved caspase-3 in Jurkat and K562 cells. (A) Jurkat and (D) K562 cells were incubated with IFA at 5,15 and $45 \mu \mathrm{M}$ for $24 \mathrm{~h}$. Western blotting was performed to detect the expression of cleaved PARP and cleaved caspase-3 in (A) Jurkat and (B) K562 cells. The ratios of (B and E) cleaved PARP and (C and F) cleaved caspase-3 to $\beta$-actin in (B and $C$ ) Jurkat and ( $E$ and $F$ ) cells were quantified using Image J software. Data are expressed as mean \pm SD of three independent experiments. ${ }^{*} \mathrm{P}<0.05,{ }^{* *} \mathrm{P}<0.01,{ }^{* * *} \mathrm{P}<0.001$ vs. control group. IFA, isoferulic acid; PARP, poly(ADP-ribose) polymerase.

manner, and decreased the proportions of Raji cells in G1 and $\mathrm{S}$ phase. Meanwhile, the percentage in G2/M phase increased from $12 \%$ to $59 \%$ upon treatment with $45 \mu \mathrm{M}$ of IFA . Fig. 2B and C show the quantification of cell arrest at G1, $\mathrm{S}$ and $\mathrm{G} 2 / \mathrm{M}$. It was also found that IFA had a similar effect on K562 (Fig. 2D-F) and Jurkat cells (Fig. 2G-I). These results revealed that IFA induced cell cycle arrest at G2/M phase in Raji, K562 and Jurkat cells.

IFA enhances apoptosis of Raji, K562 and Jurkat cells. It was further determined that significant G2/M cell cycle arrest led to cell apoptosis in Raji, K562 and Jurkat cells. As indicated in Fig. 3, using Annexin V/PI staining showed that IFA significantly triggered cell apoptosis in a dose-dependent manner in Raji, K562 and Jurkat cells,. The proportion of apoptotic 
cells increased from $7 \%$ to 24,44 and $52 \%$ (Fig. 3A and B), from $10 \%$ to 22,30 and $49 \%$ (Fig. 3C and D), and from $7 \%$ to 11,45 and $85 \%$ (Fig. 3E and F) after treatment with IFA for $24 \mathrm{~h}$ at 5, 15 and $45 \mu \mathrm{M}$ in Raji, K562 and Jurkat cells, respectively. These results suggested that IFA could promote the apoptosis of leukemia cells compared with control treatment.

IFA induces the expression of apoptotic proteins. Given that the mitochondrial-related apoptotic pathway is one of the main pathways of apoptosis (31), the effect of IFA was detected on the expression of cleaved PARP and cleaved caspase-3, two major mitochondrial apoptosis-associated proteins. Because IFA displayed more of an inhibitory effect on Jurkat cells, Jurkat cells were treated with IFA at 5, 15 and $45 \mu \mathrm{M}$ for $24 \mathrm{~h}$ (Fig. 4A). The expression of cleaved PARP and cleaved caspase-3 dramatically augmented after incubation with the indicated concentrations of IFA. Statistical analysis indicated a dose-dependent manner in IFA-induced expression of cleaved PARP and cleaved caspase-3 (Fig. 4B and C). To further confirm the effect of IFA on cell apoptosis, K562 cells were treated with IFA at 5,15 and $45 \mu \mathrm{M}$ for $24 \mathrm{~h}$; in these cells the cleavage of PARP and cleavage of caspase-3 was detected (Fig. 4D). Similarly, IFA dose-dependently increased cleaved PARP and cleaved caspase-3 levels (Fig. 4E and F). These data showed that IFA enhanced cell apoptosis by inducing the cleavage of PARP and caspase-3.

IFA modulates the phosphorylation of $C d c 2$ and expression of Cyclin B1. To further verify the effect of IFA-induced cell cycle arrest, the expression of cell cycle associated protein Cdc2 and Cyclin B1 were detected. In Fig. 5A, there was a significant increase in Cdc2 phosphorylation (Tyr15) and a decrease in the expression of Cyclin B1 after IFA treatment, compared with the control group in Jurkat cells. Fig. 5B and C showed that IFA significantly induced the phosphorylation of $\mathrm{Cdc} 2$ and attenuated the expression of Cyclin B1 in a dose-dependent manner. These results indicated that $\mathrm{G} 2 / \mathrm{M}$ phase arrest induced by IFA was associated with increased phosphorylation of $\mathrm{Cdc} 2$ and the reduction of Cyclin B1 in Jurkat cells.

IFA attenuates Akt/mTOR signaling. Since the Akt/mTOR signaling pathway plays a crucial role in cancer cell survival, it was further explored whether IFA induced apoptosis and $\mathrm{G} 2 / \mathrm{M}$ phase arrest via the modulation of Akt/mTOR signaling $(28,29)$. Jurkat cells were treated with the indicated concentrations of IFA for $24 \mathrm{~h}$. Treatment of IFA remarkably suppressed the phosphorylation of both Akt (Thr308) and mTOR (Ser2448; Fig. 5D). Additionally, a dose-dependent manner was found in the phosphorylation of Akt and mTOR after IFA treatment (Fig. 5E and F). These results indicated that IFA inhibited the Akt/mTOR signaling pathway in Jurkat cells.

\section{Discussion}

The presence of IFA leads to the dose-dependent inhibition of Raji, K562, and Jurkat cell proliferation. Microtubules are considered to be important targets for cancer treatment,
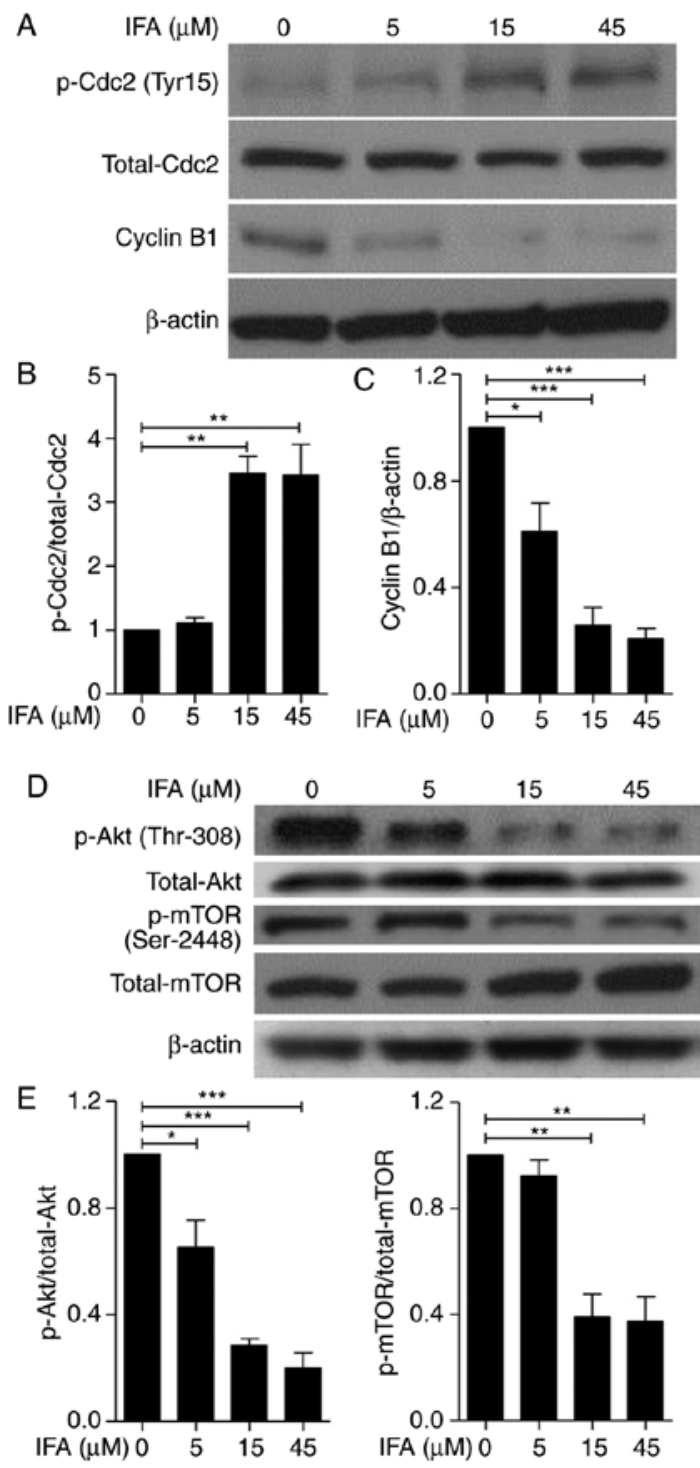

Figure 5. IFA induces the phosphorylation of $\mathrm{Cdc} 2$, and reduces the expression of Cyclin B1, as well as phosphorylation of Akt and mTOR in Jurkat cells. Jurkat cells were incubated with 5, 15 and $45 \mu \mathrm{M}$ of IFA for $24 \mathrm{~h}$. (A) Phosphorylation of Cdc2, the expression of Cyclin B1, and (D) the phosphorylation of Akt and mTOR were measured by western blotting. (B) The ratios of phosphorylation of $\mathrm{Cdc} 2$ to total $\mathrm{Cdc} 2,(\mathrm{C})$ the expression of Cyclin B to $\beta$-actin, (E) phosphorylation of Akt to total Akt, and (F) phosphorylation of mTOR to total mTOR were quantified using ImageJ software. The expression of $\beta$-actin was detected as loading control. Data are expressed as mean \pm SD of three independent experiments. ${ }^{*} \mathrm{P}<0.05,{ }^{* *} \mathrm{P}<0.01$, ${ }^{* * * *} \mathrm{P}<0.001$ vs. control group. IFA, isoferulic acid; $\mathrm{p}$, phosphorylated.

as disruption of microtubule dynamics would result in cell cycle arrest, followed by cell apoptosis (32). Paclitaxel is an effective chemotherapy drug that could inhibit microtubule formation, resulting in G2/M cell cycle arrest (33). Cell cycle analysis demonstrated that the induction of $\mathrm{G} 2 / \mathrm{M}$ phase arrest by IFA was concomitant with a decrease in G0/G1 and S phase in Raji, K562 and Jurkat cells. As is well known, activation of Cdc2, driven by Cyclin B1 binding and dephosphorylation at Tyr15 by $\mathrm{Cdc} 25 \mathrm{C}$, is an important stage in $\mathrm{G} 2 / \mathrm{M}$ phase transition. Cyclin B1 accumulation is regarded as a marker of G2/M phase arrest, since it generally accumulates in G2 phase, reaches its peak at metaphase of cell division and decreases during anaphase (34). These results indicated that IFA could 
induce G2/M phase arrest in Jurkat cells through Cyclin B1 accumulation and the inhibition of $\mathrm{Cdc} 2$ phosphorylation.

It is commonly known that programmed cell death can regulate cell survival/death balance through blockade of the cell cycle (35). A number of chemotherapeutic agents, such as doxorubicin, cisplatin and etoposide, have been shown to promote cell apoptosis by causing cell cycle arrest (36). In this study, IFA was shown to be capable of substantially increasing the level of apoptosis in Raji, K562 and Jurkat cells. In general, cell apoptosis can be activated through two signaling pathways, namely the mitochondrial pathway and the death receptor pathway (37). The mitochondrial pathway (also called the intrinsic pathway), which is mainly regulated by the Bcl-2 family, is identified as the leading apoptotic signaling pathway (36). The mitochondrial membrane potential decreases following a decrease in the intracellular $\mathrm{Bcl}-2 / \mathrm{Bax}$ ratio and an increase in the permeability of the outer mitochondrial membrane, resulting in the release of cytochrome $\mathrm{C}$ (38). The released cytochrome $\mathrm{C}$ in the cytosol can trigger the caspase cascade, after which PARP is cleaved as a substrate by caspase-3, leading to cell apoptosis (39). In this study the apoptosis evoked by IFA was shown to be associated with the upregulation of cleaved PARP and cleaved caspase-3. This suggested that IFA could induce apoptosis through the activation of mitochondria-associated intrinsic apoptosis signaling. Future studies will be aimed to determine how IFA modulates mitochondria-mediated apoptosis and which molecule is targeted by IFA.

$\mathrm{Akt} / \mathrm{mTOR}$ signaling plays a vital role in the regulation of tumor cell survival, growth and apoptosis $(23,24)$. Akt activation could prevent the release of apoptosis-stimulating factors from mitochondria by promoting the activation of antiapoptotic proteins (such as Bcl-2) and inhibiting some proapoptotic proteins (such as Bax and caspase) (40). Rapamycin analogs (rapalogs), the first generation of allosteric mTORC1 inhibitors, selectively bind to FK506 binding protein 12 of mTORC1 and inhibit mTOR signals (41). Rapalogs could reduce the proliferation of acute myeloid leukemia (AML) cells and clonogenicity of leukemic progenitor cells in preclinical and clinical settings (42). However, their effects were mainly cytostatic, partially affecting apoptosis, as confirmed in phase 1 and 2 clinical studies (43). The treatment of AML cells with a combination of PIM inhibitor AZD1897 and Akt inhibitor AZD5363 augmented the blockade of the mTOR axis and led to the induction of apoptosis (44). Since IFA had an impact on the inhibition of phosphorylation in the Akt/mTOR signal pathway, the combination of IFA and Akt inhibitors may be more effective for treatment of leukemia.

Furthermore, IFA displays various biological functions potentially beneficial in the treatment of various different diseases. Pretreatment with IFA could attenuate methylglyoxal (MG)-induced dysfunction and apoptosis in INS-1 pancreatic $\beta$-cells through the mitochondrial survival pathway and the upregulation of glyoxalase 1 activity (16). IFA derivatives also display varying degrees of anticancer potency, with some exhibiting excellent histone deacetylase inhibitory activity (45). IFA could prevent DNA damage and $\mathrm{MG}$-induced protein glycation through free radical scavenging activity (46). Dilshara et al (9) demonstrated that IFA suppresses the production of not only nitric oxide and prostaglandin E2, but also their regulatory genes in lipopolysaccharide-stimulated BV2 microglial cells by inhibiting PI3K/Akt-dependent $\mathrm{NF}-\kappa \mathrm{B}$ activity and enhancing nuclear-related factor 2-mediated heme oxygenase-1 expression. In addition, IFA may play an important role in preventing diabetic complications by inhibiting advanced glycation end product formation and oxidation-dependent protein damage (15). The present findings indicated that IFA can induce leukemia cell apoptosis and initiate apoptotic signal pathways, thus suggesting the possibility of IFA having different targets in different diseases.

In the present study, IFA inhibited p-Akt and p-mTOR, suggesting that it might inhibit Raji, K562 and Jurkat cell proliferation and induce cell apoptosis via attenuation of Akt/mTOR signaling pathway. Taken together, this study indicated the therapeutic effect of IFA on Raji, K562 and Jurkat cells, thereby suggesting it as a promising candidate for the treatment of hematologic malignancy. Conduction of in vivo experiments will be the next step to determine whether IFA can inhibit leukemia cell proliferation in mouse models, and whether it can induce apoptosis in vivo, so as to accentuate the possibility of clinical application of IFA.

\section{Acknowledgements}

Not applicable.

Funding

The present study was funded by Research Grant for Health Science and Technology of Pudong Municipal Commission of Health and family Planning of Shanghai (grant no.PW2019A-6), Shanghai Pudong Hospital Introducing Talent Research Starting Fund (grant no. 2015YJ-03) and Scientific Research Fund of Shanghai Pudong Hospital (grant no. 201503).

\section{Availability of data and materials}

The analyzed datasets generated during the present study are available from the corresponding author on reasonable request.

\section{Authors' contributions}

ZL and $\mathrm{HZ}$ designed research and revised the manuscript; GF and NZ performed the research analysis and wrote the manuscript; ZL GF NZ LW and HZ analyzed the data. All authors read and approved the final manuscript.

\section{Ethics approval and consent to participate}

Not applicable.

\section{Patient consent for publication}

Not applicable.

\section{Competing interests}

The authors declare that there is no competing interests. 


\section{References}

1. Durinck K, Goossens S, Peirs S, Wallaert A, Van Loocke W, Matthijssens F, Pieters T, Milani G, Lammens T, Rondou P, et al: Novel biological insights in T-cell acute lymphoblastic leukemia Exp Hematol 43: 625-639, 2015

2. Egler RA, Ahuja SP and Matloub Y: L-asparaginase in the treatment of patients with acute lymphoblastic leukemia. J Pharmacol Pharmacother 7: 62-71, 2016.

3. Liu XY, Yang YF, Wu CT, Xiao FJ, Zhang QW, Ma XN, Li QF, Yan J, Wang $\mathrm{H}$ and Wang LS: Spred2 is involved in imatinib-induced cytotoxicity in chronic myeloid leukemia cells. Biochem Biophys Res Commun 393: 637-642, 2010.

4. Nilsson C, Hulegårdh E, Garelius H, Möllgård L, Brune M, Wahlin A, Lenhoff S, Frödin U, Remberger M, Höglund M, et al: Secondary acute myeloid leukemia and the role of allogeneic stem cell transplantation in a population-based setting. Biol Blood Marrow Transplant 25: 1770-1778, 2019.

5. Han C and Kwon BS: Chimeric antigen receptor T-cell therapy for cancer: A basic research-oriented perspective. Immunotherapy 10: 221-234, 2018.

6. Pui CH, Relling MV and Downing JR: Acute lymphoblastic leukemia. N Engl J Med 350: 1535-1548, 2004.

7. Faderl S, O'Brien S, Pui CH, Stock W, Wetzler M, Hoelzer D and Kantarjian HM: Adult acute lymphoblastic leukemia: Concepts and strategies. Cancer 116: 1165-1176, 2010.

8. Cheng W, Zheng T, Wang Y, Cai K, Wu W, Zhao T and Xu R: Activation of Notch1 signaling by HTLV-1 Tax promotes proliferation of adult T-cell leukemia cells. Biochem Biophys Res Commun 512: 598-603, 2019.

9. Dilshara MG, Lee KT, Jayasooriya RG, Kang CH, Park SR, Choi YH, Choi IW, Hyun JW, Chang WY, Kim YS, et al: Downregulation of $\mathrm{NO}$ and PGE2 in LPS-stimulated BV2 microglial cells by trans-isoferulic acid via suppression of $\mathrm{PI} 3 \mathrm{~K} / \mathrm{Akt}$-dependent NF- $\kappa \mathrm{B}$ and activation of Nrf2-mediated HO-1. Int Immunopharmacol 18: 203-211, 2014.

10. Thiyagarajan G,MuthukumaranP,Sarath Kumar B,Muthusamy VS and Lakshmi BS: Selective inhibition of PTP1B by vitalboside a from syzygium cumini enhances insulin sensitivity and attenuates lipid accumulation via partial agonism to PPAR $\gamma$ : In vitro and in silico investigation. Chem Biol Drug Des 88: 302-312, 2016.

11. Jairajpuri DS and Jairajpuri ZS: Isoferulic acid action against glycation-induced changes in structural and functional attributes of human high-density lipoprotein. Biochemistry (Mosc) 81: 289-295, 2016.

12. Sakai S, Kawamata H, Kogure T, Mantani N, Terasawa K Umatake $\mathrm{M}$ and Ochiai $\mathrm{H}$ : Inhibitory effect of ferulic acid and isoferulic acid on the production of macrophage inflammatory protein-2 in response to respiratory syncytial virus infection in RAW264.7 cells. Mediators Inflamm 8: 173-175, 1999.

13. Wang X, Li X and Chen D: Evaluation of antioxidant activity of isoferulic acid in vitro. Nat Prod Commun 6: 1285-1288, 2011.

14. Liu IM, Hsu FL, Chen CF and Cheng JT: Antihyperglycemic action of isoferulic acid in streptozotocin-induced diabetic rats. Br J Pharmacol 129: 631-636, 2000.

15. Meeprom A, Sompong W, Chan CB and Adisakwattana S: Isoferulic acid, a new anti-glycation agent, inhibits fructose- and glucose-mediated protein glycation in vitro. Molecules 18: 6439-6454, 2013

16. Meeprom A, Chan CB, Sompong W and Adisakwattana S Isoferulic acid attenuates methylglyoxal-induced apoptosis in INS-1 rat pancreatic $\beta$-cell through mitochondrial survival pathways and increasing glyoxalase-1 activity. Biomed Pharmacother 101: 777-785, 2018

17. Nuntanakorn P, Jiang B, Einbond LS, Yang H, Kronenberg F, Weinstein IB and Kennelly EJ: Polyphenolic constituents of Actaea racemosa. J Nat Prod 69: 314-318, 2006.

18. Kim JY, Kim HY, Jeon JY, Kim DM, Zhou Y, Lee JS, Lee H and Choi HK: Effects of coronatine elicitation on growth and metabolic profiles of Lemna paucicostata culture. PLoS One 12 e0187622, 2017.

19. Xuan H, Wang Y, Li A, Fu C, Wang Y and Peng W: Bioactive components of chinese propolis water extract on antitumor activity and quality control. Evid Based Complement Alternat Med 2016: 9641965, 2016.

20. Slavin S, Nagler A, Naparstek E, Kapelushnik Y, Aker M, Cividalli G, Varadi G, Kirschbaum M, Ackerstein A, Samuel S, et al: Nonmyeloablative stem cell transplantation and cell therapy as an alternative to conventional bone marrow transplantation with lethal cytoreduction for the treatment of malignant and nonmalignant hematologic diseases. Blood 91: 756-763, 1998.
21. Ju J: An increased proportion of apoptosis in $\mathrm{CD} 4^{+} \mathrm{T}$ lymphocytes isolated from the peripheral blood in patients with stable chronic obstructive pulmonary disease. Tuberc Respir Dis (Seoul) 81: 132-137, 2018.

22. Fesik SW: Promoting apoptosis as a strategy for cancer drug discovery. Nat Rev Cancer 5: 876-885, 2005.

23. Saxena NK, Sharma D, Ding X, Lin S, Marra F, Merlin D and Anania FA: Concomitant activation of the JAK/STAT, PI3K/AKT, and ERK signaling is involved in leptin-mediated promotion of invasion and Migration of hepatocellular carcinoma cells. Cancer Res 67: 2497-2507, 2007.

24. Zhang Y, Wang SJ, Han ZH, Li YQ, Xue JH, Gao DF, Wu XS and Wang CX: PI3K/AKT signaling pathway plays a role in enhancement of eNOS activity by recombinant human angiotensin converting enzyme 2 in human umbilical vein endothelial cells. Int J Clin Exp Pathol 7: 8112-8117, 2014.

25. Ahmed MS, El-Senduny F, Taylor J and Halaweish FT: Biological screening of cucurbitacin inspired estrone analogs targeting mitogen-activated protein kinase (MAPK) pathway. Chem Biol Drug Des 90: 478-484, 2017.

26. Aoki M and Fujishita T: Oncogenic roles of the PI3K/AKT/mTOR axis. Curr Top Microbiol Immunol 407: 153-189, 2017.

27. Massagué J: G1 cell-cycle control and cancer. Nature 432: 298-306, 2004

28. Chen D, Lin X, Zhang C, Liu Z, Chen Z, Li Z, Wang J, Li B, Hu Y, Dong B, et al: Dual PI3K/mTOR inhibitor BEZ235 as a promising therapeutic strategy against paclitaxel-resistant gastric cancer via targeting PI3K/Akt/mTOR pathway. Cell Death Dis 9: 123, 2018.

29. Shimizu Y, Segawa T, Inoue T, Shiraishi T, Yoshida T, Toda Y, Yamada T, Kinukawa N, Terada N, Kobayashi T, et al: Increased Akt and phosphorylated Akt expression are associated with malignant biological features of prostate cancer in Japanese men. BJU Int 100: 685-690, 2007.

30. Yeh YC, Yang CP, Lee SS, Horng CT, Chen HY, Cho TH, Yang ML, Lee CY, Li MC and Kuan YH: Acute lung injury induced by lipopolysaccharide is inhibited by wogonin in mice via reduction of Akt phosphorylation and RhoA activation. J Pharm Pharmacol 68: 257-263, 2016.

31. Chen YJ, Su JH, Tsao CY, Hung CT, Chao HH, Lin JJ, Liao MH, Yang ZY, Huang HH, Tsai FJ, et al: Sinulariolide induced hepatocellular carcinoma apoptosis through activation of mitochondrial-related apoptotic and PERK/eIF2alpha/ATF4/CHOP pathway. Molecules 18: 10146-10161, 2013.

32. Checchi PM, Nettles JH, Zhou J, Snyder JP and Joshi HC: Microtubule-interacting drugs for cancer treatment. Trends Pharmacol Sci 24: 361-365, 2003.

33. Chang LC, Yu YL, Liu CY, Cheng YY, Chou RH, Hsieh MT, Lin HY, Hung HY, Huang LJ, Wu YC and Kuo SC: The newly synthesized 2-arylnaphthyridin-4-one, CSC-3436, induces apoptosis of non-small cell lung cancer cells by inhibiting tubulin dynamics and activating CDK1. Cancer Chemother Pharmacol 75: 1303-1315, 2015.

34. Lee MH, Cho Y, Jung BC, Kim SH, Kang YW, Pan $\mathrm{CH}$, Rhee KJ and Kim YS: Parkin induces G2/M cell cycle arrest in TNF- $\alpha$-treated HeLa cells. Biochem Biophys Res Commun 464: 63-69, 2015

35. Freeman RS, Estus S and Johnson EM Jr: Analysis of cell cycle-related gene expression in postmitotic neurons: Selective induction of Cyclin D1 during programmed cell death. Neuron 12: 343-355, 1994.

36. Montagnoli A, Moll J and Colotta F: Targeting cell division cycle 7 kinase: A new approach for cancer therapy. Clin Cancer Res 16: 4503-4508, 2010

37. Hassan M, Watari H, AbuAlmaaty A, Ohba Y and Sakuragi N: Apoptosis and molecular targeting therapy in cancer. Biomed Res Int 2014: 150845, 2014

38. Childs AC,Phaneuf SL, Dirks AJ,Phillips T and Leeuwenburgh C: Doxorubicin treatment in vivo causes cytochrome $\mathrm{C}$ release and cardiomyocyte apoptosis, as well as increased mitochondrial efficiency, superoxide dismutase activity, and Bcl-2:Bax ratio. Cancer Res 62: 4592-4598, 2002.

39. Breckenridge DG and Xue D: Regulation of mitochondrial membrane permeabilization by BCL-2 family proteins and caspases. Curr Opin Cell Biol 16: 647-652, 2004

40. Seo BR, Min KJ, Cho IJ, Kim SC and Kwon TK: Correction: Curcumin significantly enhances dual PI3K/Akt and mTOR inhibitor NVP-BEZ235-induced apoptosis in human renal carcinoma caki cells through down-regulation of p53-dependent Bcl-2 expression and inhibition of Mcl-1 protein stability. PLoS One 11: e0151886, 2016. 
41. Martelli AM, Tazzari PL, Evangelisti C, Chiarini F, Blalock WL, Billi AM, Manzoli L, McCubrey JA and Cocco L: Targeting the phosphatidylinositol 3-kinase/Akt/mammalian target of rapamycin module for acute myelogenous leukemia therapy: From bench to bedside. Curr Med Chem 14: 2009-2023, 2007.

42. Récher C, Dos Santos C, Demur C and Payrastre B: mTOR, a new therapeutic target in acute myeloid leukemia. Cell Cycle 4: 1540-1549, 2005.

43. Perl AE, Kasner MT, Tsai DE, Vogl DT, Loren AW, Schuster SJ, Porter DL, Stadtmauer EA, Goldstein SC, Frey NV, et al: A phase I study of the mammalian target of rapamycin inhibitor sirolimus and MEC chemotherapy in relapsed and refractory acute myelogenous leukemia. Clin Cancer Res 15: 6732-6739, 2009.

44. Meja K, Stengel C, Sellar R, Huszar D, Davies BR, Gale RE, Linch DC and Khwaja A: PIM and AKT kinase inhibitors show synergistic cytotoxicity in acute myeloid leukaemia that is associated with convergence on mTOR and MCL1 pathways. Br J Haematol 167: 69-79, 2014
45. Lu W, Wang F, Zhang T, Dong J, Gao H, Su P, Shi Y and Zhang J: Search for novel histone deacetylase inhibitors. Part II: Design and synthesis of novel isoferulic acid derivatives. Bioorg Med Chem 22: 2707-2713, 2014

46. Meeprom A, Sompong W, Suantawee T, Thilavech T, Chan CB and Adisakwattana S: Isoferulic acid prevents methylglyoxal-induced protein glycation and DNA damage by free radical scavenging activity. BMC Complement Altern Med 15: 346, 2015.

This work is licensed under a Creative Commons Attribution-NonCommercial-NoDerivatives 4.0 International (CC BY-NC-ND 4.0) License. 